\title{
Subclinical Hypothyroidism Prevalence in Pregnant Ladies in AL-Hilla city in Iraq
}

\author{
Ban Amer Mousa ${ }^{a}$ \\ Sijal Fadhil Farhood Al Joborae ${ }^{\text {b }}$ \\ ${ }^{a}$ Department of Gynecology and Obstetrics, collage of medicine University of Babylon \\ ${ }^{b}$ Department of Community Medicine College of Medicine, University of Babylon \\ ban200372@gmail.com_sijalaljoborae@yahoo.com
}

Submission date:- 30/4/2018

Acceptance date:- 13/6/2018

Publication date:- 1/10/2018

Keywords: Hypothyroidism, Pregnancy, Prevalence, Thyrotropin(TSH).

\begin{abstract}
Recent guidelines adapted unique pregnancy thyroid function screening tests because pregnancy subclinical hypothyroidism is associated with different adverse outcomes. There are no data from Iraq about the prevalence of thyroid hypo function in $1^{\text {st }}$ trimester of pregnancy. This study aims to find the prevalence of thyroid dysfunction in $1^{\text {st }}$ trimester.

Patients and Methods: In this descriptive cross sectional study, thyroid stimulating hormone (TSH) was measured in 100 pregnant women from May 2017-December 2017 in Babylon teaching hospital for maternity and pediatric and in private clinic. If TSH was more than $2.5 \mathrm{mIU} / \mathrm{L}$ in the first trimester, free $\mathrm{T} 4$ was measured to diagnose then differentiate between subclinical \& overt hypothyroidism. If free T4 was in the normal value (0.7$1.8 \mathrm{ng} / \mathrm{dl}$ ) the diagnosis was subclinical hypothyroidism and if below the normal value, overt hypothyroidism was diagnosed.
\end{abstract}

\section{Results}

A total of 100 pregnant women were evaluated. Twenty-eight of them were diagnosed as hypothyroidism. Subclinical hypothyroidism and overt hypothyroidism were present in $24(24 \%)$ and 4 (4\%) women respectively. Most of the subclinical and overt hypothyroidism cases were diagnosed in the first trimester.

\section{1- Introduction}

There are different studies which show decreased intellectual and motor development of babies is associated with abnormalities of their mothers thyroid function [1,2]. Thyroid gland disorders are one of the common endocrine problems in pregnant ladies. It is now well known that not only overt, but also subclinical hypothyroidism $(\mathrm{SCH})$ has adverse side effects on maternal and fetal outcome [1]. Fetal thyroid gland is not working up to 12 weeks of gestation. Thyroid releasing hormone crosses the placenta to stimulate fetal thyroid gland. So maternal thyroid function is very important during the first trimester [4]. During the first trimester, human chorionic gonadotropin (hCG) level is elevated that act similar to thyroid stimulating hormone (TSH) ( $\alpha$ subunit of hCG and TSH is similar). So the effect of TSH, under the influence of placental hCG, is low during pregnancy with the decreased TSH level in the first trimester beings poorly defined and an upper level of 2.5 mIU/L. At 10-12 weeks of gestation, plasma level of hCG begins to decline to act like TSH, so TSH is increased a little to an upper normal level of $3 \mathrm{mIU} / \mathrm{L}$ in the second and third trimester[4]. However, a study in Iraq stated that TSH level did not show significant differences in different trimesters of pregnancy. There is no data from Iraq about the prevalence of SCH in pregnancy and there is debate about unique screening of thyroid function tests in pregnancy. We, therefore, studied the thyroid function of pregnant ladies to know the prevalence of subclinical cases of hypothyroidism.

\section{2- Patients and Methods:}

This descriptive cross-sectional study was done on 100 pregnant ladies in Babylon teaching hospital for maternity and pediatrics in Alilla city and in private clinic, Babylon university of Medical Sciences . For all pregnant ladies from May 2017-December 2017 during routine laboratory workup, screening of thyroid function tests was done by TSH level in the endocrine laboratory by the chemiluminescent immunoassay (Elecsys 2010, Hitachi, Diamond, Japan). If TSH level was $>2.5 \mathrm{mIU} / \mathrm{L}$ in the first trimester or TSH $>3 \mathrm{mIU} / \mathrm{L}$ in the second or 
third trimester, free T4 measurement was done by chemiluminescent immunoassay to know whether it is subclinical or overt hypothyroidism. If serum FT4 was in the normal range (0.8-1.7 ng/dl) SCH was diagnosed and if below the normal range, overt hypothyroidism was the diagnosis. Their demographic (maternal age, gestational age, parity ,BMI, residence) and clinical details were collected as part of routine antenatal care and were recorded. We asked the women about personal and family history of thyroid disease. Duration of gestation was calculated from last menstrual period and verified by ultrasonography. Informed consent was taken from all participants. SPSS software version 20 was used for data analysis.

\section{3- Results}

Table1shows that the mean age of pregnant women who participated in the study is $26.32 \pm 6.04$ years. Regarding body mass index and weeks of gestation, the mean is $29.12 \pm 3.46 \mathrm{~kg} / \mathrm{m} 2$ and $8.0 \pm 2.06$ weeks respectively. Over half of pregnant women $(60.0 \%)$ reside in urban areas while $(40.0 \%)$ reside in rural areas .Up to $64.0 \%$ of pregnant women are multigravida.

Table 1:Distribution of the pregnant mothers according to age, BMI, GA, parity and residence.

\begin{tabular}{|l|l|l|}
\hline Age (years) & \multicolumn{2}{c|}{ Variables } \\
\hline BMI $\left(\mathrm{kg} / \mathrm{m}^{2}\right)$ & $26.32 \pm 6.04$ & $(16-40)$ \\
\hline Weeks of gestation (week) & $8.0 \pm 2.06$ & $(4-12)$ \\
\hline $\begin{array}{l}\text { Residence } \\
\text { Urban }\end{array}$ & 60 & $60.0 \%$ \\
\hline $\begin{array}{l}\text { Rural } \\
\text { Total }\end{array}$ & 40 & $40.0 \%$ \\
\hline $\begin{array}{l}\text { Parity } \\
\text { Primigravida }\end{array}$ & 100 & $100.0 \%$ \\
\hline Multigravida & 36 & $36.0 \%$ \\
\hline Total & 64 & $64.0 \%$ \\
\hline
\end{tabular}

Table 2 shows that the mean of thyroid stimulating hormone (TSH) and free T4 is $2.49 \pm 0.82$ and $1.07 \pm 0.3$ respectively.

Table 2: Distribution of the pregnant mothers according to TSH and FT4.

\begin{tabular}{|l|c|l|}
\hline Variable & Mean \pm SD & Range \\
\hline $\mathrm{TSH}^{*}(\mathrm{U} / \mathrm{ml})$ & $2.49 \pm 0.82$ & $(1.6-4.8)$ \\
& & $(0.5-1.8)$ \\
\hline FT4** $(\mathrm{ng} / \mathrm{dl})$ & $1.07 \pm 0.3$ & \\
\hline *TSH: .Thyroid stimulating hormone . **FT4:Free T4.
\end{tabular}

Figure 1 shows that subclinical hypothyroidism represents $24.0 \%$ of the total pregnant mothers in the first trimester who participated in the study while $4.0 \%$ have overt hypothyroidism. 


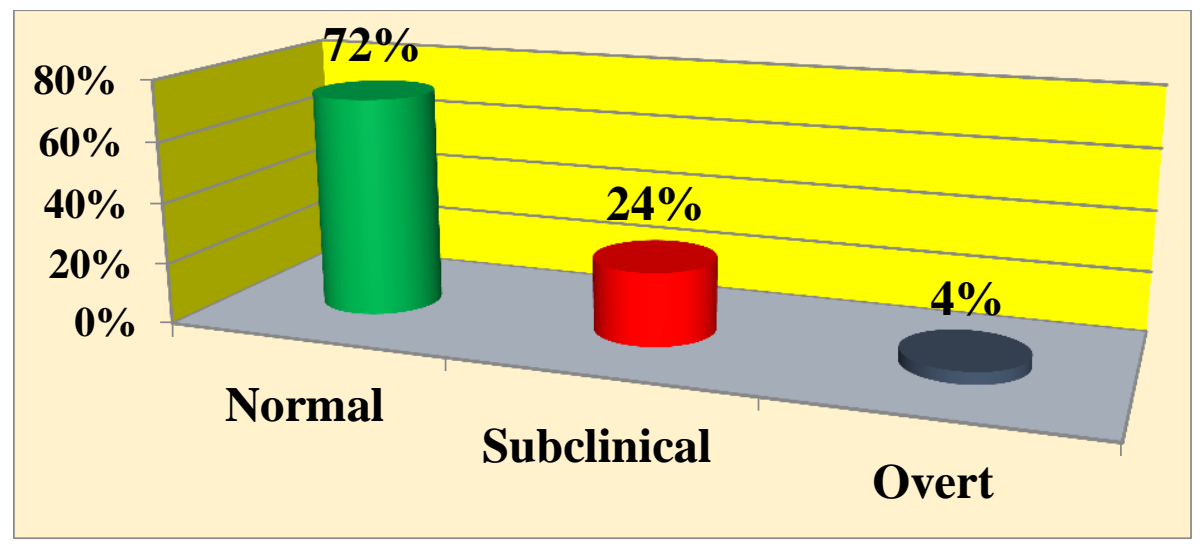

Figure 1: Distribution of pregnant mothers according to the diagnosis of hypothyroidism.

Table 3 shows that fisher exact test was conducted to show the association between parity, residence with the diagnosis of hypothyroidism. There is a significant association between residence and diagnosis $(\mathrm{p}$-value $<0.001)$

Table 3: Association between parity, residence and diagnosis of hypothyroidism.

\begin{tabular}{|c|c|c|c|c|c|}
\hline \multirow[t]{2}{*}{ Variables } & \multicolumn{3}{|c|}{ Diagnosis } & \multirow[t]{2}{*}{ Total } & \multirow[t]{2}{*}{$\mathrm{P}$ - value } \\
\hline & Normal & Subclinical & Overt & & \\
\hline \multicolumn{6}{|l|}{ Parity } \\
\hline Primigravida & $24(33.3 \%)$ & $12(50.0 \%)$ & $0(0.0 \%)$ & $36(36.0 \%)$ & $0.1^{\mathrm{f}}$ \\
\hline Multigravida & $48(66.7 \%)$ & $12(50.0 \%)$ & $4(100.0 \%)$ & $64(64.0 \%)$ & \\
\hline Total & $72(100.0 \%)$ & $24(100.0 \%)$ & $4(100.0 \%)$ & $100(100.0 \%)$ & \\
\hline \multicolumn{6}{|l|}{ Residence } \\
\hline Urban & $52(72.2 \%)$ & $8(33.3 \%)$ & $0(0.0 \%)$ & $60(60.0 \%)$ & $<0.001 *^{\mathrm{f}}$ \\
\hline Rural & $20(27.8 \%)$ & $16(66.7 \%)$ & $4(100.0 \%)$ & $40(40.0 \%)$ & \\
\hline Total & $72(100.0 \%)$ & $24(100.0 \%)$ & $4(100.0 \%)$ & $100(100.0 \%)$ & \\
\hline
\end{tabular}

$* \mathrm{P}$ - value $\leq 0.05$ was significant. $\quad$ f:fisher-exact test.

In this table, F-test (ANOVA) was conducted to show if there were mean differences of age ,BMI and weeks of gestation according to diagnosis of hypothyroidism( normal ,subclinical or overt ).In all circumstances there were significant mean differences ( $\mathrm{p}$-value $<0.001 *$ ) 
Table 4: Mean difference of age, BMI and GA according to diagnosis of hypothyroidism in pregnant women.

\begin{tabular}{|l|l|l|l|l|l|}
\hline Variable & Study groups & $\mathrm{N}$ & Mean \pm SD & F- test & P-value \\
\hline Age (year) & Normal & 72 & $26.89 \pm 5.67$ & 22.66 & $<0.001^{*}$ \\
\hline & Subclinical & 24 & $22.33 \pm 2.8$ & & \\
& Overt & 4 & $40.0 \pm 0.0$ & & $<0.001^{*}$ \\
\hline BMI $\left(\mathrm{kg} / \mathrm{m}^{2}\right)$ & Normal & 72 & $28.06 \pm 2.77$ & 31.52 & \\
& Subclinical & 24 & $30.83 \pm 2.72$ & & $<0.001^{*}$ \\
\hline Overt & 4 & $38.0 \pm 0.0$ & & \\
\hline Week of gestation(week) & Normal & & & & \\
& Subclinical & 72 & $7.11 \pm 1.49$ & 45.63 & \\
\hline & Overt & 24 & $10.17 \pm 1.6$ & & \\
\hline & & 4 & $11.0 \pm 0.0$ & & \\
\hline
\end{tabular}

$* \mathrm{P}$ - value $\leq 0.05$ was significant.

Figure 2 :-This figure shows that there was a significant negative linear correlation between TSH and FT4(p-value $=0.011^{*}, \mathrm{r}=-0.252$ )

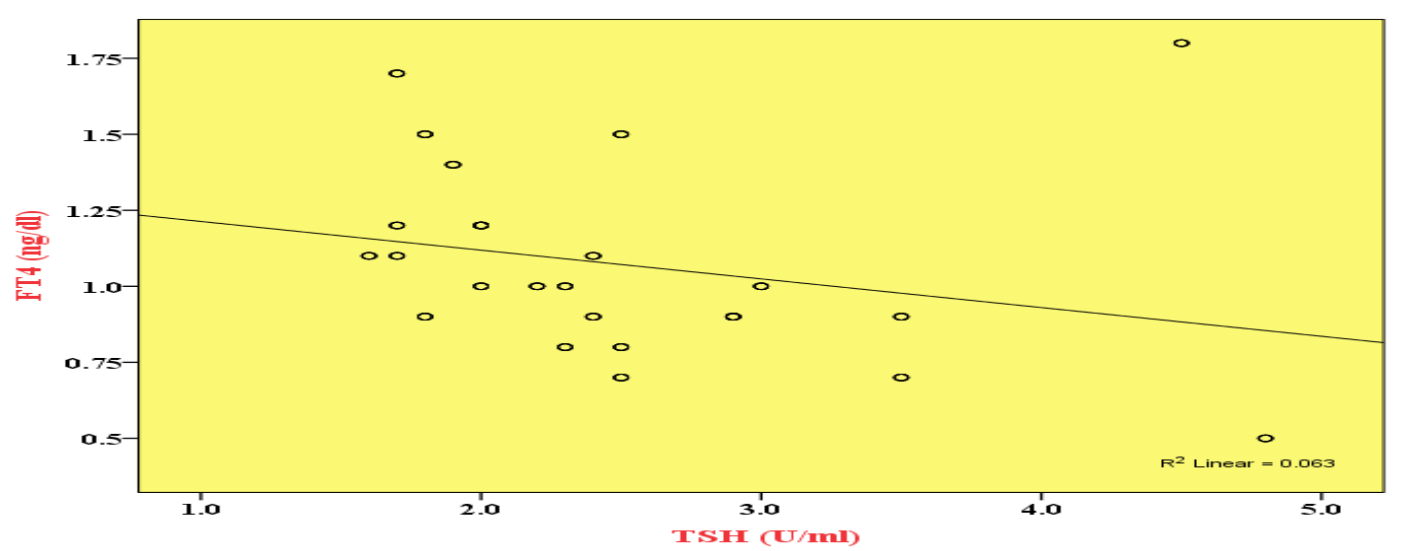

Figure 2: Correlation between TSH and FT4.

Figure 3 depicts that there was a significant mean difference of TSH according to age, $(\mathrm{p}$-value $=0.006)$. Regarding FT4 also there was a significant mean difference according to age,$(p$ value $=0.03)$ 


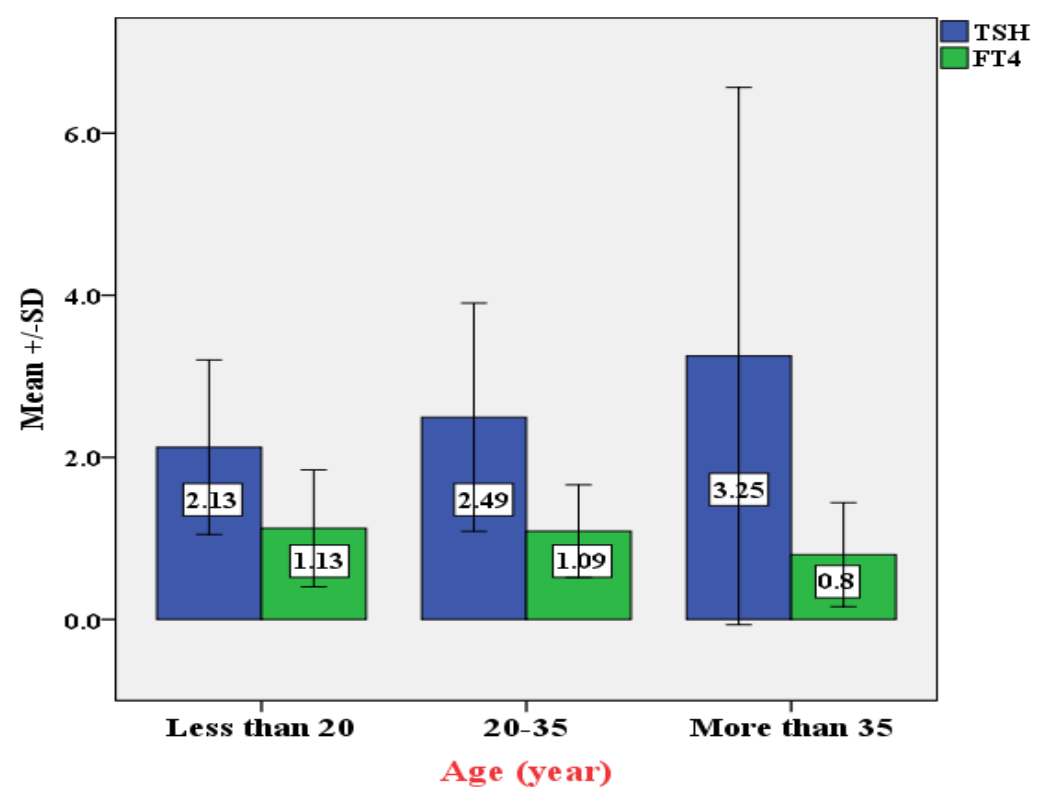

Figure 3: Distribution of TSH and FT4 according to the age of the pregnant mothers.

Figure 4 depicts the higher percentage of subclinical cases of hypothyroidism was present in women aged 20- 35 years $(83.3 \%)$, while those aged younger than 20 years , the percentage was $16.7 \%$

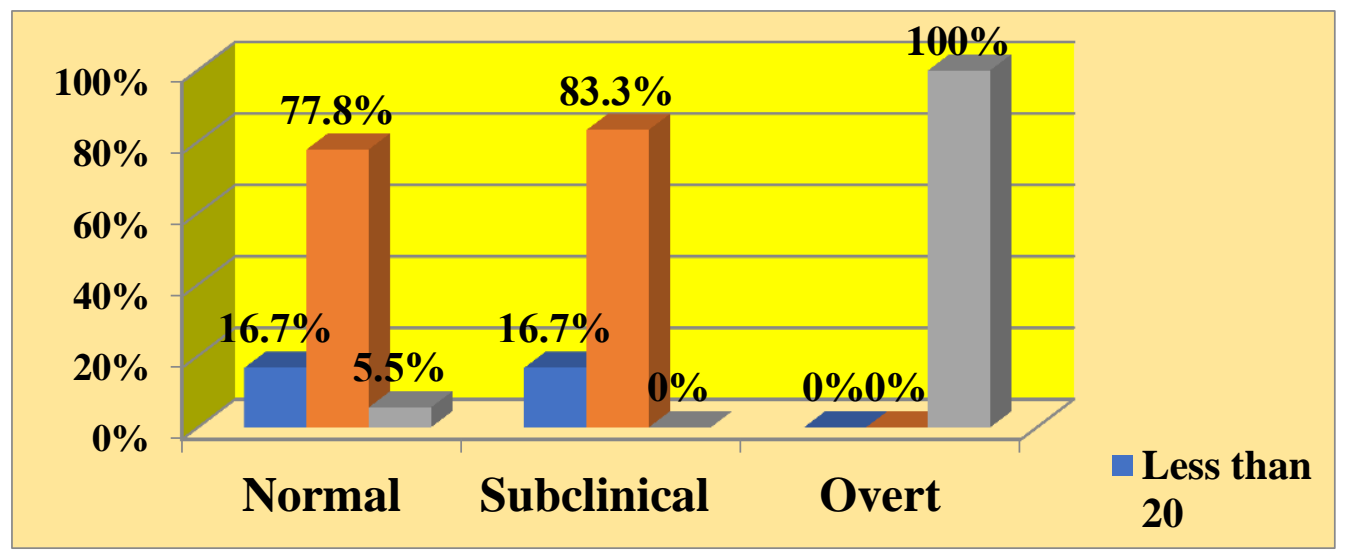

Figure 4: Association between age of the pregnant women and diagnosis.

\begin{abstract}
4-Discussion
We found the prevalence of subclinical hypothyroidism to be $6.15 \%$. According to the study by Casey et al. the prevalence of subclinical hypothyroidism during early pregnancy is common, affecting about $5.5 \%$ pregnant women [7, 8]. A similar result was reported by Allan et al. [9], Vaidya et al. [10] and Mannisto et al. [11]. These studies are in contrast with the report by Gillett who stated that routine screening of pregnant women is not necessary for thyroid function, unless they were at increased risk of thyroid disease [12].

This suggests that subclinical hypothyroidism is more common in pregnant women especially in Iraqi pregnant ladies. Subclinical hypothyroidism during early pregnancy has been shown to be associated with the impaired neuropsychological development of children and several other adverse outcomes, including preterm delivery, preeclampsia and increased fetal mortality $[1,4,8,10,11,13-16]$. But the study by Cleary Goldman et al. showed that subclinical hypothyroidism is detectable in $2.2 \%$ in the first and second trimesters with no adverse outcome in pregnant women with thyroid hypofunction [15]. Pregnancy has much influence on the thyroid gland and thyroid
\end{abstract}


function. Physiological changes of pregnancy cause the thyroid gland to increase production of thyroid hormones to meet maternal and fetal needs. TSH and human chorionic gonadotropin (hCG) have identical $\alpha$ subunits whereas the $\beta$ subunits differ in their amino acid sequence[4]. There is also an uncertainty regarding the most appropriate initial screening test for thyroid dysfunction in pregnancy. The consensus guidelines recommend using TSH level as the initial test $[10,14,16]$. The American College of Obstetricians and Gynecologists (2007) concluded that although observational data were consistent with the possibility that subclinical hypothyroidism was associated with adverse neuropsychological development, there have been no interventional trials to demonstrate improvement in decision to do routine thyroid screening of pregnant women. There are reports that testing the high-risk group only for thyroid function would miss about one third of pregnant women with overt/subclinical hypothyroidism [7, 9, 17-22]. Most of our patients with overt hypothyroidism were diagnosed in the first trimester. This is in agreement with a previous study by Sahu et al. in India in which the rate of overt hypothyroidism was reported as $4.6 \%$ [3]. We know that patients with overt hypothyroidism usually are infertile and if they become pregnant, complications of pregnancy such as abortion may occur. So universal screening for thyroid function appears logical. Also, diagnosis of subclinical hypothyroidism during the third trimester is necessary to treat them and prevent postpartum depression.

\section{5- Conclusion}

There is a high percentage of pregnant women that reach second and third trimester of pregnancy with undiagnosed thyroid disease. It is , therefore, necessary to screen women with a serum TSH, if they are pregnant or deciding to become pregnant to overcome the complications that may occur due to maternal hypothyroidism.

\section{CONFLICT OF INTERESTS}

\section{There are no conflicts of interest.}

\section{6- References}

[1] J.E. Haddow, et al." Maternal thyroid deficiency during pregnancy and subsequent neuropsychological development of the child",N Engl J Med ;341(8): 549-555;1999.

[2]Z. Shan, et al." Abnormalities of maternal thyroid function during pregnancy affect neuropsychological development of their children at 25-30 months". Clin Endocrinol (Oxf) ;72(6):825-829; 2010 .

[3] MT. Sahu, V. Das, S. Mittal, A. Agrawal and M. Sahu." Overt and subclinical thyroid dysfunction among Indian pregnant women and its effect on maternal and fetal outcome". Arch Gynecol Obstet ; 281(2):215220. 2010.

[4] A. Stagnaro-Green, et al. "Guidelines of the American Thyroid Association for the diagnosis and management of thyroid disease during pregnancy and postpartum Thyroid "; 21(10):1081-1125, 2011.

[5] O.P. Soldin, R.E. Tractenberg, J.G. Hollowell, J. Jonklaas, N. Janicic and S.J. Soldin. "Trimester-specific changes in maternal thyroid hormone, thyrotropin, and thyroglobulin concentrations during gestation: trends and associations across trimesters in iodine sufficiency Thyroid"; 14(12) :1084-1090; 2004.

[6] N. Zarghami, M. Rohbani-Noubar and A. Khosrowbeygi." Thyroid hormones status during pregnancy in normal Iranian women \& Indian J Clin Biochem." ; 20(2):182-185. 2005

[7] B.M .Casey, J.S. Dashe, C.Y. Sponge, D.D. McIntire, K.J. Leveno and G.F. Cunningham." Perinatal significance of isolated maternal hypothyroxinemia identified in the first half of pregnancy". Obstet Gynecol ;109(5):1129-1135, 2007.

[8] B.M. Casey, et al. "Subclinical hypothyroidism and pregnancy outcomes". Obstet Gynecol; 105 (2):239245; 2005.

[9] W.C. Allan, et al." Maternal thyroid deficiency and pregnancy complications: implications for population screening".J Med Screen. ;7(3):127-130; 2000.

[10] B.Vaidya , et al. "Detection of thyroid dysfunction in early pregnancy: Universal screening or targeted high risk case finding? ", J Clin Endocrinol Metab. ; 92 (1) : 203 - 207 ; 2007.

[11] T. Männistö , et al." Perinatal outcome of children born to mothers with thyroid dysfunction or a antibodies: a prospective population-based cohort study". J Clin Endocrinol Metab. ;94(3):772-779; 2009.

[12] M.Gillett." Subclinical hypothyroidism: Subclinical thyroid disease: Scientific review and guidelines for diagnosis and management". Clin Biochem Rev. ; 25(3):191-194; 2004.

[13]M. Abalovi, et al." Overt and subclinical hypothyroidism complicating pregnancy". Thyroid;12(1):6368; 2002. 
[14]A. Kourtis, et al. "Prevalence of undiagnosed thyroid disease in pregnancy." Endocrine Abstracts. ; 22:794794; 2010.

[15] J.Cleary-Goldman, et al."Maternal thyroid hypo function and pregnancy outcome". Obstet Gynecol;112(1):85-92, 2008.

[16] VJ. Pop,et al. " Maternal hypothyroxinemia during early pregnancy and subsequent child development: a 3year follow-up study". Clin Endocrinol (Oxf) ; 59 : 282 -288; 2003.

[17] R. Negro,et al." Universal screening versus case finding for detection and treatment of thyroid hormonal dysfunction during pregnancy". J Clin Endocrinol Metab. ;95(4):1699-1707; 2010.

[18] McLeod DSA and McIntyre HD. "Subclinical hypothyroidism and related biochemical entities in pregnancy:implications and management". Obstet Med. ; 3 (4) :139-144; 2010.

[19] LE. Davis, KJ. Leveno and FG. Cunningham." Hypothyroidism complicating pregnancy". Obstet Gynecol.;72(1):108-112; 1988.

[20] N . Benhadi, et al ." Higher maternal TSH levels in pregnancy are associated with increased risk for miscarriage, fetal or neonatal death". Eur J Endocrinol ;160 (6) : 985 - 991; 2009.

[21] W . Wang, et al. "The prevalence of thyroid disorders during early pregnancy in China: the benefits of universal screening in the first trimester of pregnancy". Eur J Endocrinol. ;164 (2) :263-268; 2011.

[22] G . Ashoor, et al ." Maternal thyroid function at 11 to 13 weeks of gestation and subsequent fetal death". Thyroid ;20 (9) : 989-993; 2010.

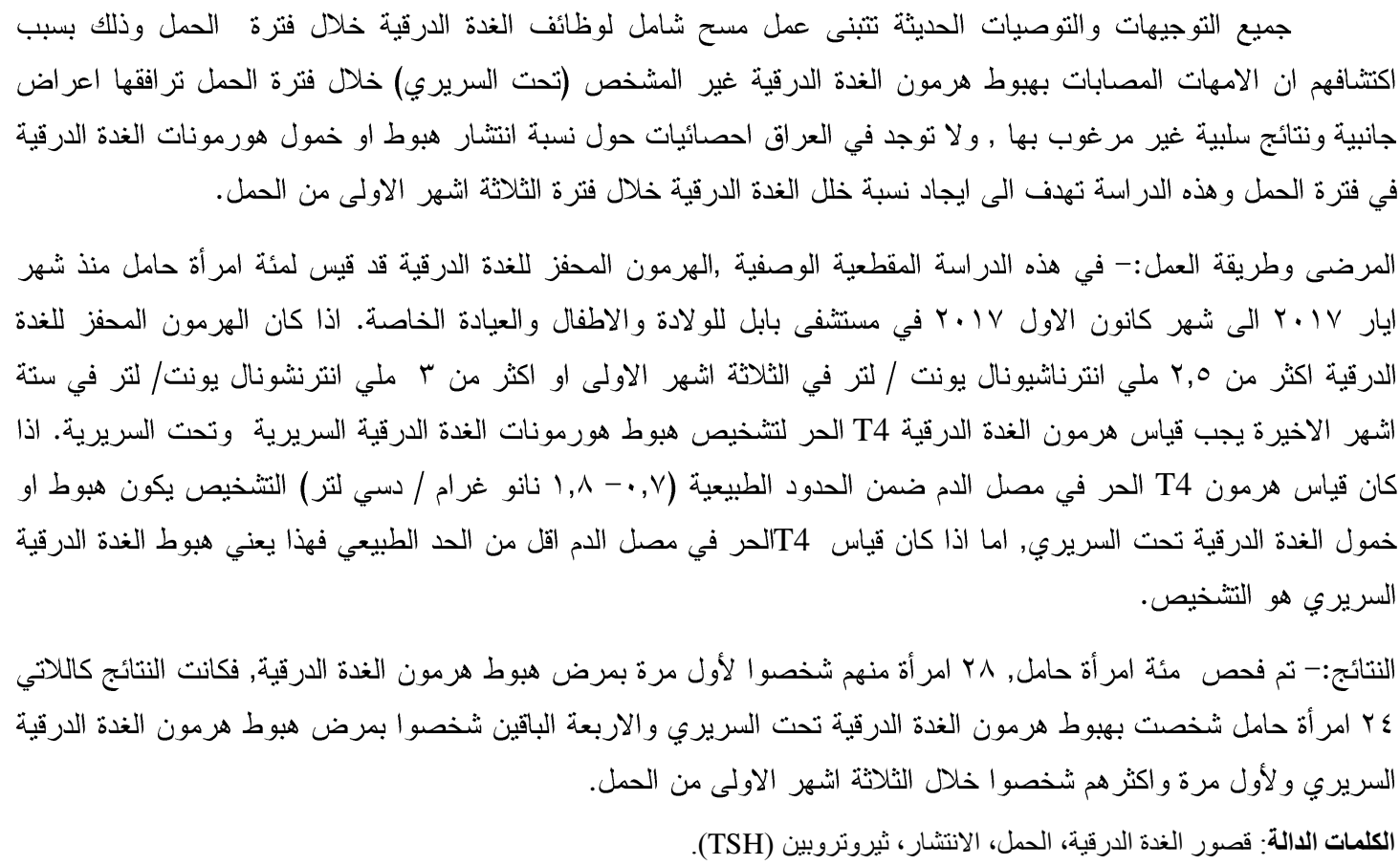

